DOT/FAA/AM-07/19

Office of Aerospace Medicine

Washington, DC 20591

\title{
Selective Serotonin Reuptake Inhibitors: Medical History of Fatally Injured Aviation Accident Pilots
}

Ahmet Sen

Ahmet Akin

Gülhane Military Medical Academy

Department of Aerospace Medicine

Eskisehir 26020, Turkey

Dennis V. Canfield

Arvind K. Chaturvedi

Civil Aerospace Medical Institute

Federal Aviation Administration

Oklahoma City, OK 73125

July 2007

Final Report 


\section{NOTICE}

This document is disseminated under the sponsorship of the U.S. Department of Transportation in the interest of information exchange. The United States Government assumes no liability for the contents thereof.

This publication and all Office of Aerospace Medicine technical reports are available in full-text from the Civil Aerospace Medical Institute's publications Web site: www.faa.gov/library/reports/medical/oamtechreports/index.cfm 
Technical Report Documentation Page

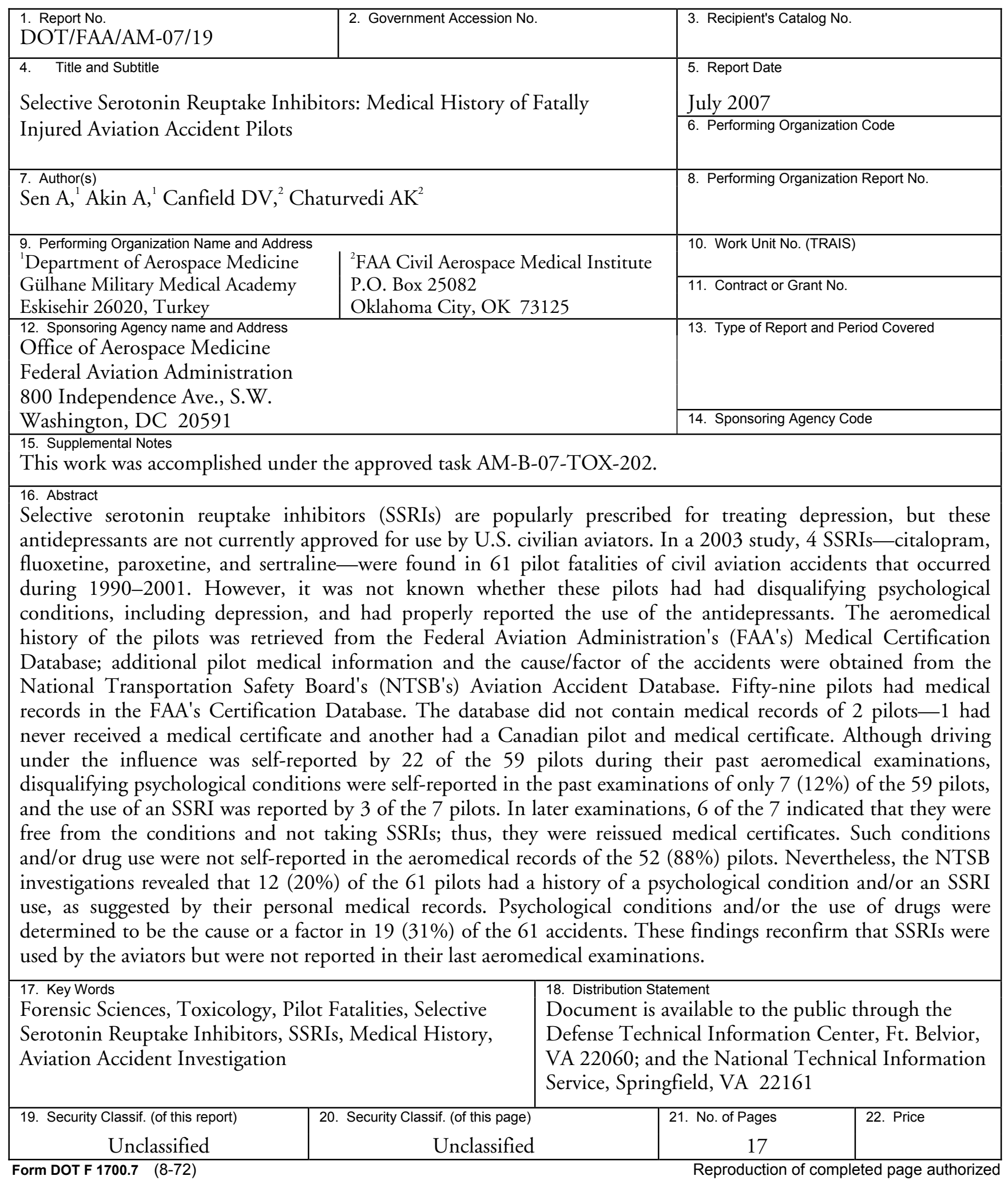





\section{ACKNOWLEDGMENTS}

The Government of Turkey is acknowledged for allowing the participation of Dr. Ahmet Akin and Dr. Ahmet Sen in the Federal Aviation Administration (FAA) International Exchange Visitor Program at the FAA Civil Aerospace Medical Institute, Oklahoma City, Oklahoma.

The authors are grateful to Dr. Selim Kilic, Department of Epidemiology, Gülhane Military Medical Academy, Ankara, Turkey, for performing statistical analyses. 



\section{Selective Serotonin Reuptake Inhibitors: Medical History of Fatally Injured Aviation Accident Pilots}

\section{INTRODUCTION}

The treatment of depression has become more effective after the advent of selective serotonin reuptake inhibitors (SSRIs). This new generation of antidepressants is better tolerated by patients $(11,15)$. Therefore, they are popularly prescribed in comparison to older antidepressants (10), but SSRIs are not currently approved for use by U.S. civilian aviators $(5,13)$.

The use of SSRIs by pilots and the associated flight safety concerns have been widely discussed $(7,8,14,17)$. An Aerospace Medical Association position paper stated that, according to the Aviation Medicine Advisory Service database of pilots' telephone inquiries, approximately $15 \%$ of pilots who had been advised by their physicians to take antidepressant medications showed an intention to take the medications and continue flying without informing the Federal Aviation Administration (FAA). However, the number of active aviators using SSRIs without authorization is not known (8).

In a 2003 study by Akin and Chaturvedi (1), the prevalence of SSRIs in civil aviation accident pilot fatalities was evaluated. The study revealed that SSRIs - citalopram, fluoxetine, paroxetine, and sertraline-were found in 61 of 4184 pilot fatalities of U.S. civil aviation accidents that occurred during 1990-2001. The use of an SSRI was found to be a contributing factor by the National Transportation Safety Board (NTSB) in 9 of the 61 accidents, but the reports of all 61 accidents were not finalized at the time of the study. Although toxicological findings, flight categories, and pilot certificates of the 61 SSRI-involved pilot fatalities were discussed thoroughly in the study (1), it was not known whether these pilots had disqualifying psychological conditions, including depression, and had properly reported the use of the antidepressants in their past aviation medical examinations. Therefore, as a continuation of the earlier study, the present study was conducted to reveal the medical history of those 61 pilots and the cause/factors of all the associated 61 accidents.

\section{METHODS}

\section{Aviation Medical Examinations}

All U.S. civilian pilots are required to have periodical aviation medical examinations (2). Examination reports are submitted to FAA's Civil Aerospace Medical Institute's
(CAMI's) Aerospace Medical Certification Division online and/or through regular mail by Aviation Medical Examiners (AMEs). Additional medical information, such as specialist reports or laboratory test results, is also submitted to CAMI. All submitted information is stored both as hard copies and digitally in the Aerospace Medical Certification Division.

\section{Database Search}

Past aviation medical examination reports of each of the 61 SSRI-involved pilots were searched through the CAMI Medical Certification Database (Oklahoma City, $\mathrm{OK})$. Available personal medical histories of the pilots were obtained through the accident reports from the NTSB Aviation Accident Database (Washington, DC). Information on the types of airman medical certificates held by these pilots was retrieved from the CAMI Certification Database and from the NTSB Aviation Accident Database. The number of fatal aviation accidents reported by the NTSB for the 1990-2001 period was obtained from the FAA's National Aviation Safety Data Analysis Center (NASDAC) Database (Washington, DC). The information for the 61 SSRI-related accidents, including the probable cause and contributing factors of those accidents, as determined and reported by the NTSB, was retrieved from the NTSB Aviation Accident Database. Since the NASDAC Database includes information primarily associated with the registered aircraft accidents, information on the unregistered aircraft accidents may not necessarily be included in this database. It should be noted that not all of the pilots involved in the accidents had appropriate airman flying and/or medical certificates to fly an aircraft.

\section{Statistics}

The proportion (percentage) of the SSRI-involved fatal accidents/pilot fatalities in the total pilot fatalityinvolved accidents/pilot fatalities per year, as retrieved from the CAMI Toxicology Database (Oklahoma City, OK), was calculated for each year from 1990 to 2001. The difference of percentages in years was analyzed by Chi-square test using SPSS $₫$ for Windows ${ }^{\circledR} 10.0$ (SPSS Inc., Chicago, IL). A trend was obtained by plotting the proportional values against the corresponding years by using Microsoft ${ }^{\circledR}$ Office Excel 2003 (Redmond, WA). 


\section{RESULTS}

Pilot Demographics and Accident Characteristics

The age, flight time (hours), time between the accident and the last aviation medical examination, and time between the first and the last aviation medical examination (estimated total years of flight) of the SSRIinvolved pilots are presented in Table I. The age of the pilots ranged from 27 to 71 years. The flying experience of pilots, expressed as total flight hours and estimated total flight years, was distributed on a wide range of 5 to 25,678 hours and 0 to 36 years, respectively. The median points were correspondingly 900 flight hours and 17 years. This group of pilots consisted of 1 female and 60 males. Professions of the 61 pilots were listed as: businessmen, 21; medical professionals, 13; professional pilots, 6; and others, 10 (ranchers, lawyers, engineers, aircraft mechanics, and retired individuals). Of the 13 medical professionals, 2 were psychiatrists and 1 was a psychologist. The professions of 11 were not known.

Of the 61 accidents, 56 happened in general aviation, 2 air taxi and commuter, and 3 agricultural flights. Of the 56 general aviation accidents, 35 pilots held private ( 1 of them had a Canadian flying certificate), 10 commercial, 4 airline transport, 3 student, and 1 recreational airman flying certificates. Three pilots were non-certificated. All 5 pilots of the air taxi and commuter and agricultural flights held commercial airman flying certificates (Fig. 1).

Out of the 61 pilots, 3 held First-Class, 12 SecondClass, and 34 Third-Class medical certificates ( 1 of them had a Canadian medical certificate). Medical certificates of 5 pilots had been deferred or denied; certificates of 6 pilots were expired at the time of the accident. One pilot did not have a certificate. Two of the Second-Class medical certificate holders were involved in air taxi and commuter flights and 3 in agricultural flights. The remaining 56 pilots were involved in general aviation accidents (Fig. 2).
The percentages of the SSRI-involved pilot fatalities, with respect to the total number of pilot fatalities (cases) during the 12-year period from which postmortem samples were received at CAMI, clearly suggest a drastic increase in the number of fatalities with these medications by 2001 (Fig. 3). For example, the SSRI-associated fatalities/aviation accidents increased from $0.26 \%$ in 1991 to $5.88 \%$ in 2001 . The difference in the proportions of the SSRI-involved fatal accidents/pilot fatalities in the total fatal accidents/pilot fatalities per year was statistically significant $($ Chi-square $=61.303 ; \mathrm{df}=11 ; \mathrm{p}<0.001)$.

\section{Aeromedical History of the SSRI-Associated Pilots}

Medical records of 59 pilots were found in the CAMI Certification Database. The database did not contain information about 1 pilot who had never received a medical examination. Another pilot had a Canadian medical certificate.

Twenty-two of the 59 pilots had self-reported a history of convictions involving driving under the influence (DUI). Additionally, 1 pilot had reported a history of alcohol abuse.

Eight pilots were found in the Certification Database with diagnosis related or attributable to psychiatric disorders or psychological conditions. One of these pilots had failed to report a diagnosis of a disorder/condition, and it was not discovered by the AME during medical examination. However, the Regional Flight Surgeon's office did discover information from a court decision and subsequently from the treating physician's report that the pilot had a history of "attempted suicide." Seven of the 8 pilots had self-reported a history of psychiatric or psychological conditions. Three of these 7 pilots had reported the use of an SSRI as well.

Of the 7 pilots, 1 had reported a history of "unconsciousness," 1 "mental disorder," 1 "alcohol abuse," 1 "unspecified neurotic disorder" (prescribed fluoxetine), 2 "depression" ( 1 of them was taking paroxetine), and 1

Table I. Aeromedical Characteristics of the 61 SSRI-Involved Pilots

\begin{tabular}{|c|c|c|c|c|}
\hline $\begin{array}{l}\text { Statistical } \\
\text { Parameters }\end{array}$ & $\begin{array}{c}\text { Age } \\
(\mathrm{n}=61)\end{array}$ & $\begin{array}{l}\text { Flight Hours } \\
\quad(\mathrm{n}=61)\end{array}$ & $\begin{array}{c}\text { Time Between the Accident } \\
\text { and the Last Aviation Medical } \\
\text { Examination } \\
(\text { Months; } \mathrm{n}=59)\end{array}$ & $\begin{array}{l}\text { Time Between the First and } \\
\text { the Last Aviation Medical } \\
\text { Examination* } \\
\text { (Years; } \mathrm{n}=59)\end{array}$ \\
\hline Min & 27 & 5 & 2 & 0 \\
\hline Max & 71 & 25678 & 118 & 36 \\
\hline Mean & 52.0 & 2811.6 & 16.7 & 16.7 \\
\hline SD & 11.3 & 5440.1 & 18.3 & 12.4 \\
\hline Median & 53 & 900 & 12 & 17 \\
\hline
\end{tabular}

*Estimated total flight years. 


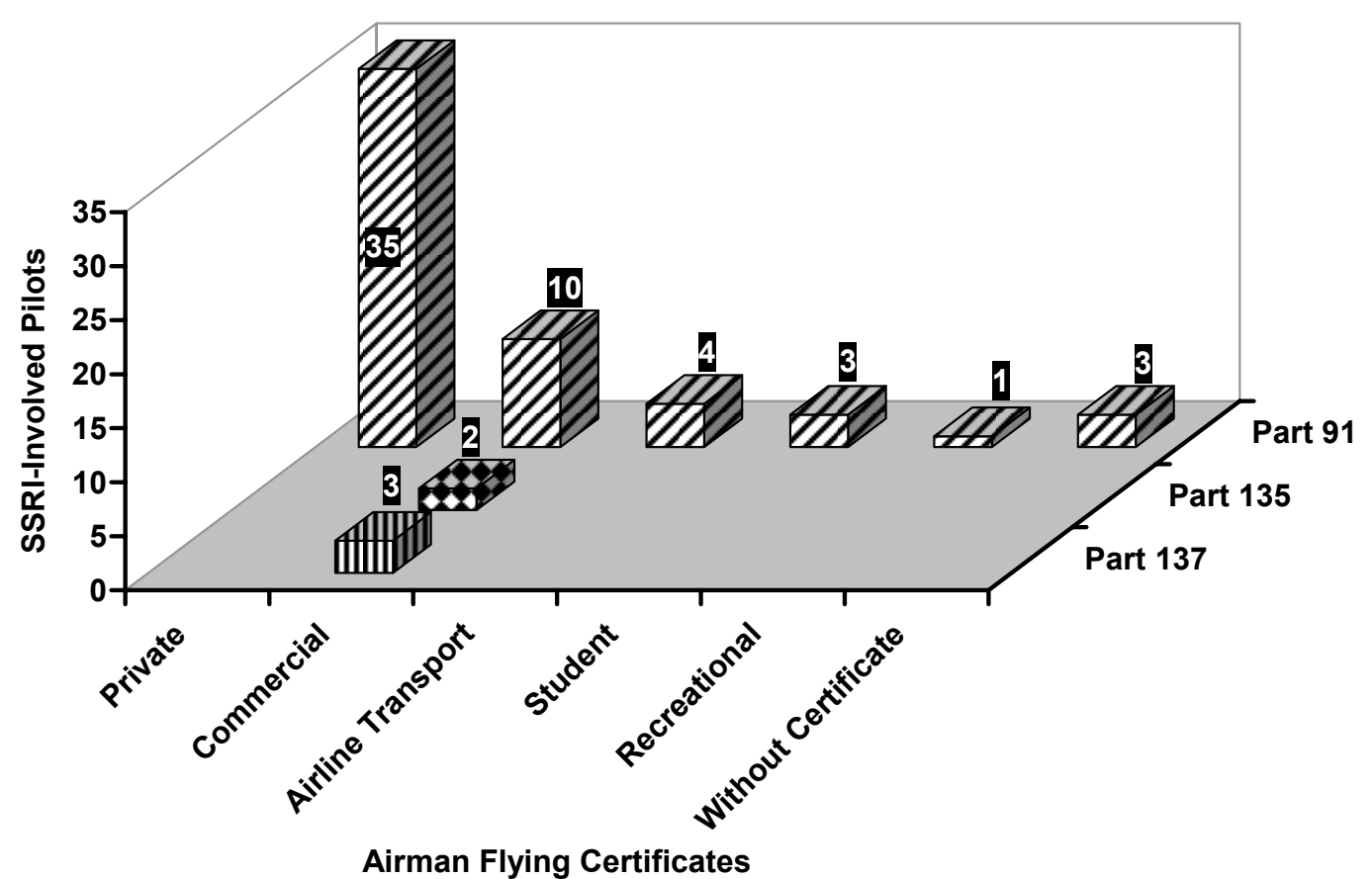

Figure 1. SSRI-associated pilot fatalities with respect to airman flying certificates and flight categories of the aircraft involved in the fatal accidents, 1990-2001 (3). Part 91, general aviation; Part 135, air taxi and commuter; Part 137, agricultural.

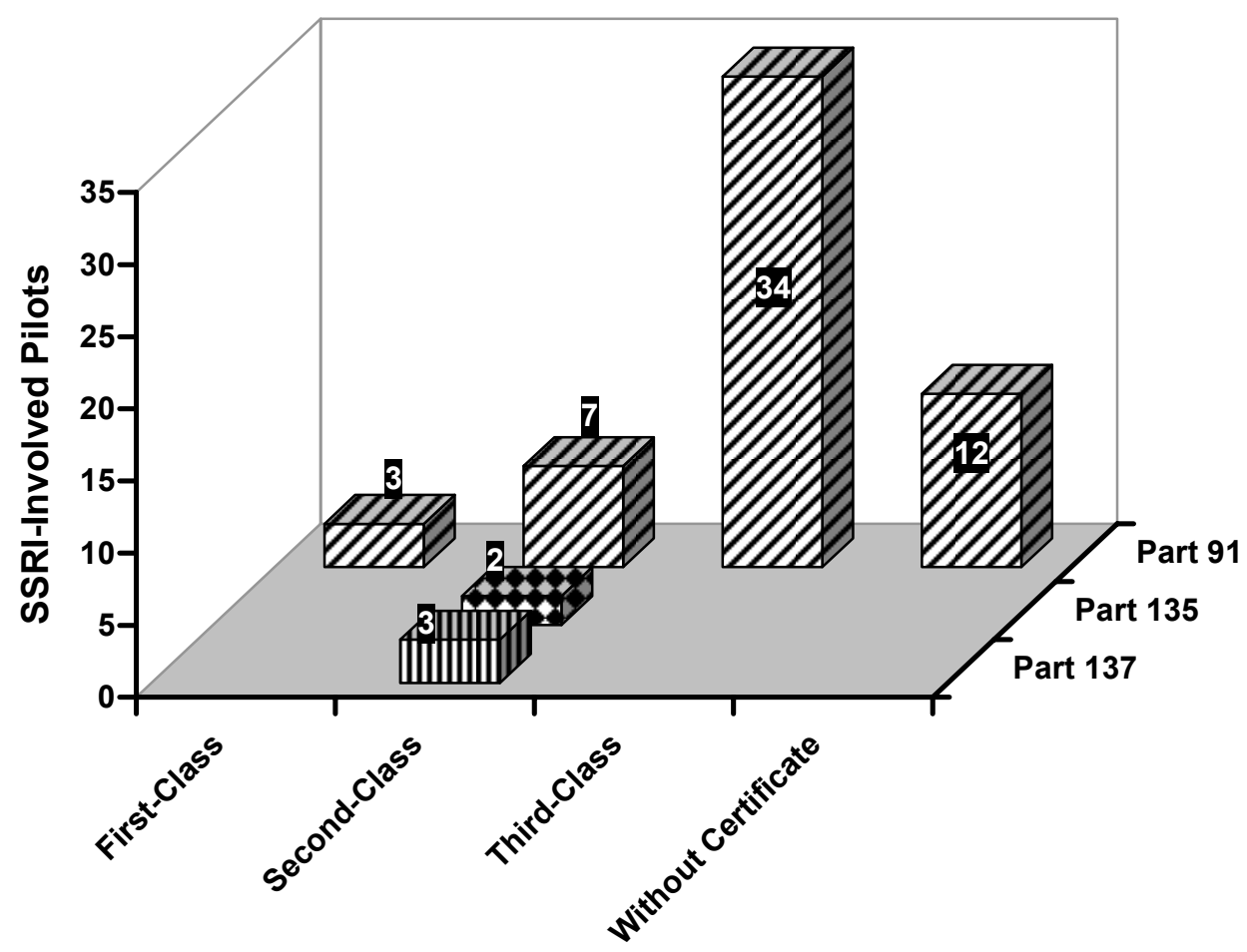

Airman Medical Certificates

Figure 2. SSRI-involved pilot fatalities with respect to airman medical certificates and flight categories of the aircraft associated with the fatal accidents, 1990-2001 (3). Part 91, general aviation; Part 135, air taxi and commuter; Part 137, agricultural. 


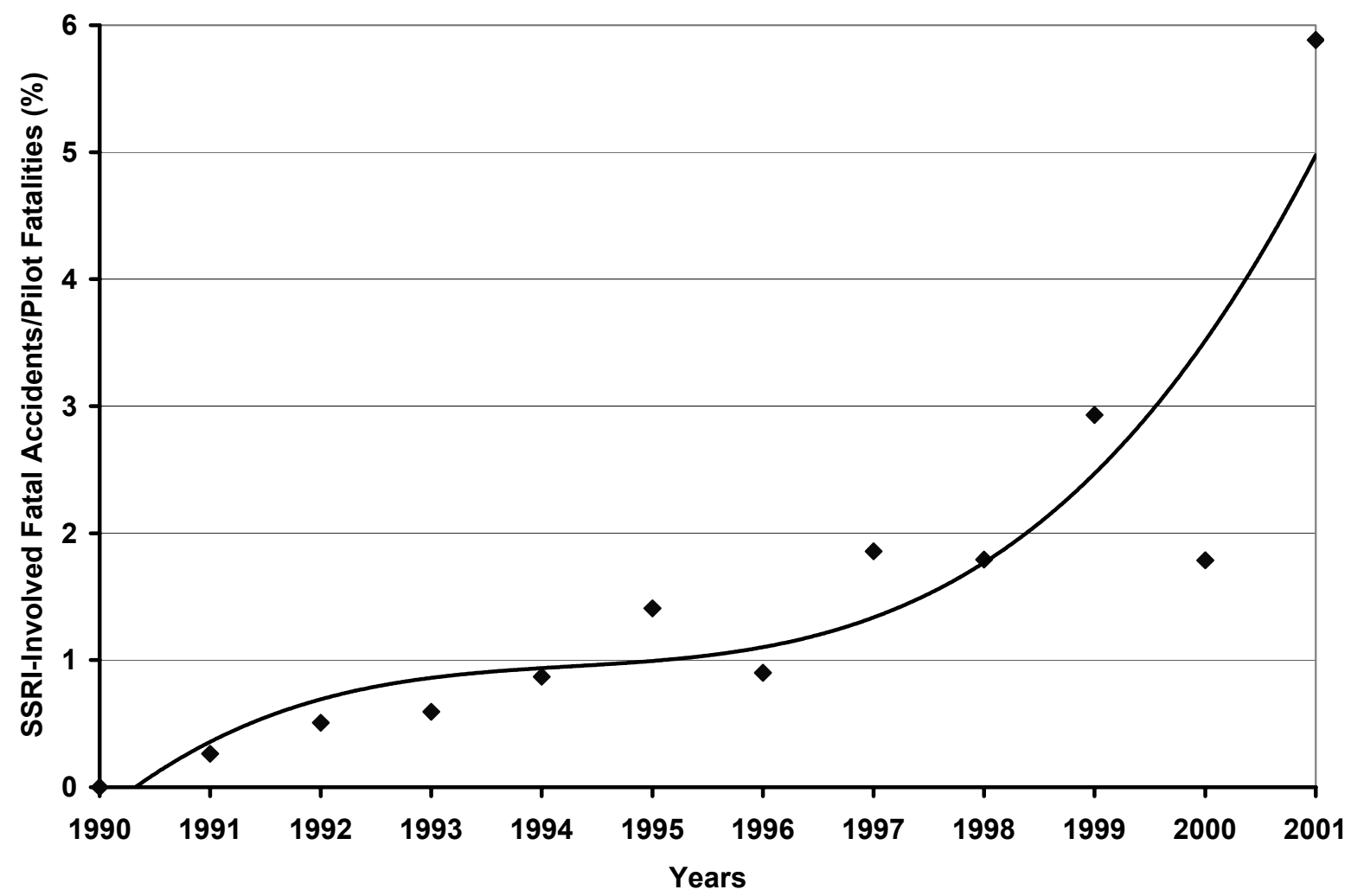

Figure 3. The percentage of the SSRI-involved fatal accidents/pilot fatalities in the total pilot fatality-involved accidents/pilot fatalities per year from which samples were received at CAMI for toxicological evaluation during 1990-2001. There is a statistically significant difference in percentages with respect to years $($ Chi-square $=61.303 ; \mathrm{df}=11 ; \mathrm{p}<0.001)$.

"anxiety" (taking sertraline). Also, 6 of the 7 pilots had reported and/or submitted specialist reports denying that they had the disqualifying conditions or were being treated with the disqualifying medications. Therefore, they were reissued medical certificates. However, 1 pilot with a diagnosis of depression was deferred by the AME and was not issued a medical certificate. The pilot's deferred medical examination was conducted 32 months before being involved in a fatal accident.

\section{Personal Medical History}

The personal medical records retrieved from the NTSB accident reports suggested that 12 of the 61 pilots had a history of SSRI use and/or a diagnosis related to psychiatric disorders or psychological conditions. Such disorders/conditions were also reported in the CAMI aeromedical certification records of 2 of the 12 pilots, but no related record was found for the remaining 10. The personal medical records of 3 of the 12 pilots indicated that they had used an antidepressant without any indication of psychiatric diagnosis - 2 of them were taking sertraline and 1 an unspecified antidepressant. Five pilots had the diagnosis of "depression" (2 were prescribed fluoxetine, 1 citalopram, and 1 paroxetine), 1 "panic disorder" and was prescribed fluoxetine, 1 "bipolar disorder" and was prescribed fluoxetine, 1 "adult attention deficit disorder" (AADD) and was prescribed an unspecified AADD medication, and 1 "anxiety" and was prescribed paroxetine.

\section{Psychological Conditions andlor SSRI Use as Aviation} Accident Cause/Factor

Based on the information available in the NTSB Database, accident reports of all 61 accidents have been finalized. Accordingly, the NTSB reports indicated that in 19 of the 61 accidents psychological conditions and/ or the use of drugs by pilots were the probable cause or contributing factors (Table II). The probable cause of 1 accident was undetermined. The cause/factor(s) of the remaining 41 accidents were not associated with drug use or medical conditions.

In 1 accident, the probable cause was determined to be "suicide." "Pilot's other psychological condition" was also a factor in this accident. "Pilot's impairment (alcohol) and his psychological condition" was reported as contributing factors in 1 accident. In another accident, "pilot's alcoholic and drug impairment" was the probable cause, and "pilot's impairment due to alcohol" was reported as causal in 1 accident, wherein "his psychological condition" was also a contributing factor. In 1 accident, the findings were "the 
Table II. The SSRI-Involved Accidents Wherein the Psychological Conditions and/or the Use of SSRIs and/or Other Drugs Were Determined by the NTSB to be the Cause/Factor(s)

\begin{tabular}{|c|c|c|}
\hline Accident & Probable Cause & Contributing Factor(s) \\
\hline 1 & Suicide & Other psychological condition \\
\hline 2 & - & Use of a prescription drug \\
\hline 3 & $\begin{array}{l}\text { Alcoholic and drug impairment of efficiency } \\
\text { and judgment }\end{array}$ & - \\
\hline 4 & - & $\begin{array}{l}\text { Impairment due to use of drugs that were not } \\
\text { approved for use while flying }\end{array}$ \\
\hline 5 & $\begin{array}{l}\text { Impairment of judgment and performance due } \\
\text { to drugs }\end{array}$ & - \\
\hline 6 & Loss of control due to spatial disorientation & Impairment due to medication \\
\hline 7 & - & Use of contraindicated drugs \\
\hline 8 & - & Use of unapproved medication \\
\hline 9 & Physiological impairment due to alcohol & Psychological condition \\
\hline 10 & - & $\begin{array}{l}\text { Impairment of the pilot's judgment by the } \\
\text { use of a contraindicated drug, and his } \\
\text { overconfidence in his abilities }\end{array}$ \\
\hline 11 & - & $\begin{array}{l}\text { Use of prescription drugs not approved for } \\
\text { use by the FAA }\end{array}$ \\
\hline 12 & Alcohol impaired decision making & - \\
\hline 13 & The pilot's incapacitation & $\begin{array}{l}\text { Inappropriate use of medication, and } \\
\text { depression }\end{array}$ \\
\hline 14 & - & Impairment due to drugs/medication \\
\hline 15 & - & $\begin{array}{l}\text { Pilot's impairment (alcohol), and his } \\
\text { psychological condition }\end{array}$ \\
\hline 16 & - & $\begin{array}{l}\text { Drug impairment of the pilot as a result of } \\
\text { higher than normal levels of Benadryl }\end{array}$ \\
\hline 17 & - & Use of FAA prohibited drugs \\
\hline 18 & - & Impairment (drugs) of the private pilot \\
\hline 19 & - & Use of inappropriate medications \\
\hline
\end{tabular}

*Findings. 
pilot's depression" and "inappropriate use of medication." The "use of drugs" (an SSRI with or without other drugs) was found to be the probable cause in 1 accident and a contributing factor in 11 . The cause of 1 accident was "pilot's alcohol impaired decision making;" a contributing factor in another was "impairment of the pilot as a result of higher than normal levels of Benadryl," wherein an SSRI was also present.

\section{DISCUSSION}

The use of SSRIs by aviators has attracted a great deal of discussion $(7,8,14,17)$, and some authors and professional associations recommended a policy for developing criteria to allow the use of the antidepressants by selected pilots (8). Currently, U.S. regulations do not permit the use of antidepressants by civilian aviators $(2,5)$. Nevertheless, some countries have different policies about SSRI use by aviators. For example, Canadian aviation authorities have an aeromedically supervised treatment protocol that allows a few pilots to fly "with or as copilots" during maintenance antidepressant therapy $(8,9)$, and the Australian Civil Aviation Safety Authority has allowed during January 1993-June 2004 nearly 500 pilots and air traffic controllers to return to duty while their depression was under control with SSRIs $(4,12)$. However, safety concerns have been raised about the details of these procedures (6).

Aviation safety concerns have also been raised for the risk potential of depressed and untreated pilots and for the pilots receiving SSRIs without informing the AME or the FAA $(7,8)$. Furthermore, based on the pilots' telephone inquiries database of Aviation Medicine Advisory Service, it has been reported that, when instructed about the current regulations banning the use of SSRIs by airmen, $59 \%$ of the pilots preferred to refuse the medication and continue to fly. However, about $15 \%$ said that they would prefer to take the medications without informing the FAA (8). Another safety issue that has been reported by the FAA officials shows that the problem is not solely with the pilots' incorrect decision but, in some instances, with AMEs' practices as well $(14,16)$. The U.S. Federal Air Surgeon addressed this problem: "Unfortunately, we recently became aware of more than 100 airmen that had been issued certificates while they were taking selective serotonin reuptake inhibitors, or SSRIs"(16).

Although the number of active pilots using SSRIs cannot be easily and clearly established, the only group of pilots with documented SSRI use was the one reported in the study of Akin and Chaturvedi (1), wherein SSRIs were found in 61 pilot fatalities of U.S. civil aviation accidents (1990-2001). That study was based on the postmortem toxicological data and did not contain information on the medical history of these airmen. In continuation of the postmortem study, the present study found that none of the 61 pilots was certificated mistakenly. Of the 7 pilots who initially self-reported a history of psychological condition, only 1 was not reissued a medical certificate after the pilot's last aviation medical examination, which was conducted 32 months before being involved in a fatal accident. The other 6 pilots had declared that they had no longer had a disqualifying medical condition, and/or they had not been taking a disqualifying medication. Furthermore, personal medical records of 2 of these pilots and an additional 10 pilots showed that they had been on regular treatment with antidepressants. Although $88 \%$ $(52 / 59)$ of the pilots had not reported their psychiatric condition and $95 \%(56 / 59)$ had never reported the use of an antidepressant, the higher percentage of reporting of a DUI-39\% (23/59) — was an interesting observation. The reporting of DUIs in such relatively high numberscompared to the reporting of SSRI use-could have been because the FAA has the authority to access the records of pilots from the National Driver Registry. Also, some pilots may have assumed that they could continue to fly even with a history of DUI. This observation might support the suggestion that a policy allowing a supervised maintenance SSRI use could prevent airmen from using SSRIs without informing the FAA $(7,8)$. However, the use of SSRIs may be underreported, similar to the situation in which only $1 \%$ of Australian pilots were identified as having been certificated while taking SSRIs (12). The $1 \%$ value was considered to be much lower than that of the general population, suggesting that the SSRI use was underreported.

Although the majority of the SSRI-involved fatal aviation accident pilots were certificated, and they were primarily private pilot and Third-class medical certificate holders, there were a number of pilots $(20 \%$; $12 / 61)$ that chose to fly without valid medical certificates. In the group of 61, there were experienced and inexperienced aviators, ranging from young to old age groups. Interestingly, 21\% of them were medical professionals -2 of them were psychiatrists and 1 was a psychologist.

In the earlier study by Akin and Chaturvedi (1), the use of an SSRI was reported as a contributory factor in 9 of 61 accidents. At that time, the reports of all 61 accidents had not been finalized by the NTSB. All the 61 reports have now been completed, and accordingly, pilot's psychological condition and/or SSRI use was reported to be the probable cause or a contributing factor in $31 \%$ $(19 / 61)$ of the accidents.

Findings from the present study reconfirm that SSRIs were used by aviators, but the use was not reported in 
their last aeromedical examinations. Additionally, most of the the airmen had not self-reported their psychological conditions and medications while they were continuing a regular SSRI treatment. Even the pilots with medical backgrounds and education did not report their conditions or medications. Since the problem of not reporting the use of SSRI and/or psychiatric diagnosis continues, AMEs should use caution in certifying airmen with vague psychological signs, particularly when the use of this group of antidepressants is drastically increasing in the society.

\section{REFERENCES}

1. Akin A, Chaturvedi AK. Selective serotonin reuptake inhibitors in pilot fatalities of civil aviation accidents, 1990-2001. Aviat Space Environ Med 2003; 74:1169-76.

2. Code of Federal Regulations. Title 14-Aeronautics and space, Chapter I (1-1-06 Edition)—Federal Aviation Administration, Department of Transportation, Subchapter D-Airmen, Part 67-Medical standards and certification. Washington, DC: GPO, 2006.

3. Code of Federal Regulations. Title 14-Aeronautics and space, Chapter I (1-1-06 Edition)-Federal Aviation Administration, Department of Transportation, Subchapter F-Air traffic and general operating rules and Subchapter G-Air carriers and operators for compensation or hire: certification and operations. Washington, DC: GPO, 2006.

4. Emonson D. Letter to the editor. Aviat Space Environ Med 2002; 73:1241.

5. Federal Aviation Administration, Office of Aerospace Medicine. Guide for aviation medical examiners, retrieved 9/25/2006, from www.faa. gov/about/office_org/headquarters_offices/avs/ offices/aam/ame/guide.
6. Ireland RR. In response to the letter by Emonson. Aviat Space Environ Med 2002; 73:1241.

7. Ireland RR. Pharmacologic considerations for serotonin reuptake inhibitor use by aviators. Aviat Space Environ Med 2002; 73:421-9.

8. Jones DR, Ireland RR. Aeromedical regulation of aviators using selective serotonin reuptake inhibitors for depressive disorders. Aviat Space Environ Med 2004; 75:461-70.

9. Lange M. Maintenance SRI use in professional pilots: the Canadian experience [abstract]. Aviat Space Environ Med 2002; 73:244.

10. Latner AW. The top 200 of 2000 : Drugs of the new millennium. Pharm Times 2001; 67(4):14-29.

11. Physicians' desk reference. 60th ed. Montvale, NJ: Thomson PDR, 2006.

12. Ross J, Crisp D, Lambeth L, et al. Antidepressant usage and civilian aviation activity in Australia 1993-2004. Canberra, Australia: Civil Aviation Safety Authority; 2005 Sep.

13. Silberman WS. Medications in civil aviation: what is acceptable and what is not? Aviat Space Environ Med 2003; 74:85-6.

14. Silberman WS. SSRI policy reminder. Fed Air Surg Med Bull 2005; 43(2):9.

15. Sweetman SC, ed. Martindale: the complete drug reference. 34th ed. London: Pharmaceutical Press, 2005.

16. Tilton F. The Federal Air Surgeon's ColumnThanks. Fed Air Surg Med Bull 2006; 44(2):2.

17. Van Syoc D. Serotonin reuptake inhibitors in aircrew [abstract]. Aviat Space Environ Med 2002; $73: 244$. 
